\title{
Eva Perón: a mulher e o mito no conto "Esa mujer", de Rodolfo Walsh
}

Eva Perón: the woman and the myth in the short story "Esa mujer", by Rodolfo Walsh

\section{Letícia Malloy}

Universidade Federal de Minas Gerais - UFMG-MG - Minas Gerais - Brasil

\section{André Tessaro Pelinser}

Universidade de Caxias do Sul - UCS - Caxias do Sul - Brasil

\begin{abstract}
Resumo: Relatos históricos, biografias e registros da memória oral têm construído uma significativa gama de sentidos em torno de Eva Perón. Interpretações - não raro apaixonadas - atribuem àquela personagem histórica as condições de santa, prostituta, abnegada mãe de seu povo, perspicaz estrategista, mulher de personalidade masculina etc. A narrativa literária, em diálogo com o contexto político argentino do século XX, também participa do processo de construção de significados atribuídos a Eva Perón. Este trabalho objetiva analisar o modo como o mito Eva Perón é apresentado no conto "Esa mujer", de Rodolfo Walsh. Para tanto, adotam-se como referenciais teóricos os escritos de Gilbert Durand e Roland Barthes sobre 0 imaginário e os mitos na contemporaneidade. Além disso, leva-se em consideração a poética do escritor e militante Rodolfo Walsh.
\end{abstract}

Palavras-chave: Eva Perón. Representações discursivas. Construções míticas.

Abstract: Historical reports, biographies, and records based on oral memory have built an expressive range of meanings relating to Eva Perón. Interpretations - recurrently passionate - attribute to that historical character the features of saint, prostitute, abnegated mother of her people, perspicacious strategist, woman with male personality etc. The literary narrative, setting out a dialogue with Argentina's political context concerning the 20th century, also takes part in the process of construction of meanings assigned to Eva Perón. This paper aims at analysing the way Eva Perón's myth is portrayed in Rodolfo Walsh's short story entitled "Esa mujer". For such purpose, we take as main theoretical references the writings of Gilbert Durand and Roland Barthes on imaginary and myths in contemporaneity. Furthermore, we take into consideration the poetics of the writer and militant Rodolfo Walsh.

Keywords: Eva Perón. Discursive representations. Mythical constructions. 
Meu sofrimento nunca há de ser tão grande, quanto gloriosa será minha morte! Sófocles, Antígona

\section{Introdução: a construção mítica de Eva Perón}

Narrativas históricas, biografias e registros da memória oral têm contribuído para a construção de um importante plexo de sentidos em torno da figura de Eva Perón. Interpretações não raro orientadas pelos sentimentos de amor e de ódio atribuem àquela personagem histórica as condições de santa, prostituta, abnegada mãe de seu povo, perspicaz estrategista, mulher de personalidade masculina, dentre outros tantos significantes dotados das mais variadas cargas semânticas. Rastrear e tentar definir Eva Perón, seus diversos desdobramentos e representações discursivas parecem ser tarefas tão complexas e de resultado tão incerto quanto o desafio de percorrer o espaço borgeano de uma biblioteca. Se no espaço criado por Borges (1974, p. 465), "desde cualquier hexágono, se ven los pisos inferiores y superiores: interminablemente", na face daquela polivalente personalidade argentina também podem ser encontradas imagens múltiplas - a de María Eva, Eva, Eva Duarte, Evita, Eva Perón etc.

A composição mítica de Eva Perón é fomentada por interpretações histórico-sociais, políticas e, também, por textos como Mi Mensaje e Razón de mi Vida, de autoria atribuída à própria Eva1. Em ambos os trabalhos, a ex-primeira-dama argentina faz uso de um jogo de luz e sombra no qual, aparentemente, oscila entre a exaltação de seu destino e a diminuição de sua importância em face do mestre Juan Domingo Perón. Para tanto, elabora a seguinte afirmação: "Es que - lo reconozco - yo he dejado de existir en mi misma y es él quien vive en mi alma, dueño de todas mis palabras y de mis

\footnotetext{
1 Razón de mi Vida foi publicado em 1951, ao passo que Mi Mensaje, último e inacabado trabalho de Eva Perón, esteve perdido de 1952 a 1987. Neste ponto, importa observar que os trabalhos sobre o mito Eva Perón costumam apresentar, como ponto de partida, textos literários como os contos "Ella" (1953), de Juan Carlos Onetti, "El Simulacro" (1953), de Jorge Luis Borges, e "La señora muerta" (1963), de David Viñas. Adotando perspectiva diversa, a professora Mónica Liliana Bueno, da Universidade Nacional de Mar del Plata, estuda tal composição mítica a partir dos textos da própria Eva Perón. A pesquisa da referida professora argentina é intitulada "Experiência y mito: la figura de Eva Perón”, e encontra-se em desenvolvimento.
}

sentimientos, señor absoluto de mi corazón y de mi vida". (PERÓN, 1951, p. 47) Se por um lado Eva Perón põe a si mesma em função do marido, por outro potencializa a mitificação de sua própria figura ao possibilitar uma relação intertextual com certa passagem da Carta de Paulo aos Gálatas. Nesta, Paulo certifica: "Assim já não sou eu quem vive, mas Cristo é quem vive em mim." (BÍBLIA SAGRADA, 1969, p. 225). Enquanto aquele discípulo cristão teve a história marcada por uma profunda reforma íntima de Saulo a Paulo de Tarso -, no caso argentino podese pensar na sugestão de uma transformação interior sofrida por Eva Duarte para tornar-se Eva Perón. Tal mudança só teria sido possível devido à presença de Juan Domingo Perón em sua vida, de modo análogo ao que ocorrera com Paulo mediante a figura de Cristo. Observa-se, assim, um movimento narrativo que, para elevar a figura de Eva Perón, reforça conjuntamente a imagem de seu marido.

Nessa linha de raciocínio, a autora se compara ora a um condor (PERÓN, 1951, pp. 122; 222) que precisa voar tão alto quanto o esposo, ora a "um ramo de flores" (PERÓN, 2012, s/p) cuja função seria apenas a de enfeitar a casa e a vida de Juan Domingo Perón. Nas duas passagens citadas, Eva transita pelos "mitos da polaridade", um dos níveis míticos organizados por Gilbert Durand em seu As estruturas antropológicas do imaginário (2002). Recorrendo a Mircea Eliade, o teórico identifica a coincidentia oppositorum que caracteriza diversos conjuntos míticos por meio de pareamentos, a princípio paradoxais, capazes de conjugar em uma só personalidade as características de destruidora e benevolente. (DURAND, 2002, p. 290). Como no caso de muitos dos deuses mencionados por Durand, Eva Perón constrói para si mesma uma imagem dotada tanto de força quanto de fragilidade, de altivez e brandura, esboçando a complexa polaridade que concorre para sua mitificação não só após a morte, mas ainda em vida.

Essa dinâmica pendular parece ser uma constante na estrutura narrativa de Mi Mensaje e Razón de mi vida. Eva é a jovenzinha pobre e de pouco estudo, mas não deixa de ser a mulher capaz 
de analisar o panorama político de seu tempo e de se referir a figuras pretéritas, como Alexandre e Napoleão. (PERÓN, 2012, s/p) Em um trecho de Mi Mensaje, que pode ser interpretado como emotivo e estratégico, ela coopera com a elaboração mítica de sua própria figura ao manifestar, por exemplo, o desejo de estar entre o povo argentino mesmo após sua morte ${ }^{2}$ :

Desearía también que los pobres, los ancianos, los niños, mis descamisados, sigan escribiéndome como lo hacen en estos tiempos de mi vida y que el monumento que quiso levantar para mi el Congreso de mi Pueblo recoja las esperanzas de todos y las convierta en realidad por medio de mi Fundación, a la que quiero siempre pura como la concebí para mis descamisados. Así yo me sentiré siempre cerca de mi pueblo y seguiré siendo el puente de amor tendido entre los descamisados y Perón. (PERÓN, 2012, s/p).

Os textos de Eva Perón se coadunam com a perspectiva barthesiana de construção das mitologias. Segundo Roland Barthes (1999, p. 110), o mito é uma composição que se dá no âmbito da linguagem. Vale lembrar, ainda que este ensaio não trate dos conceitos de "linguagem" e "fala", que Barthes utiliza ambos os sintagmas no que toca à elaboração do mito. O teórico francês esclarece que "entenderemos por lenguaje, discurso, habla, etc., toda unidad o toda síntesis significativa, sea verbal o visual; para nosotros, una fotografía será un habla de la misma manera que un texto de jornal." (BARTHES, 1999, p. 100) O processo de construção do mito, como pontua o autor, não ocorre por meio de enunciações aleatórias: “(...) el mito constituye un sistema de comunicación, un mensaje. Esto indica que el mito no podría ser un objeto, un concepto o una idea; se trata de un modo de significación, de una forma." (BARTHES, 1999, p. 108)

Com efeito, frutificadas não só por seus próprios textos, como pelos textos que outros construíram embasados em sua figura e pela gama de analogias então possíveis, as relações que podem ser traçadas a partir da persona de Evita delineiam

\footnotetext{
2 Como já afirmado, a elaboração mítica de Eva Perón em vida vem sendo tratada de modo pormenorizado no estudo "Experiência y mito: la figura de Eva Perón”, de Mónica Liliana Bueno.
}

um conjunto de sentidos agrupados por um imaginário bastante coeso. Sua figura se torna um referencial, em cujo entorno orbita um modo de significação, uma forma de ver não só a experiência da liderança política, como também a experiência humana de determinado momento histórico. Os significados díspares agregados pelo ser real e imaginado Eva Perón ultrapassam, assim, as fronteiras políticas para se arvorarem em um todo independente, em uma mensagem capaz de significar as experiências de determinado período da história argentina.

Nesse sentido, se Eva Perón recebeu seus primeiros contornos míticos em vida, cumpre observar que o mistério do cadáver embalsamado de Evita foi um evento determinante para a formação de uma espécie de nimbo em torno de seu nome e de sua imagem. Desde 1952, ano de seu falecimento, o corpo vinha sendo mantido no edifício da Confederação Nacional do Trabalho (CGT) e seria de lá transferido para um mausoléu destinado à visitação pública. Em 1955, todavia, o cadáver foi retirado do prédio da CGT mediante ordem proferida pelos líderes da denominada "Revolução Libertadora" golpe militar que acarretou a queda e o exílio de Juan Domingo Perón. O sumiço do corpo, ocorrido por determinação de militares, deu ensejo à elaboração de narrativas orais e nutriu um duradouro imaginário acerca daquela mulher que, morta, mas hipoteticamente não enterrada, mantinha laços com seu povo.

\section{A construção do mito Eva Perón: ressonâncias em âmbito literário}

O tema do falecimento de Eva Perón rendeu frutos no âmbito literário, como pode ser verificado nos contos "Ella" (1953), de Juan Carlos Onetti, "El Simulacro" (1953), de Jorge Luis Borges, e "La señora muerta" (1963), de David Viñas. De maneiras distintas, as três narrativas contêm indicadores da reação popular à morte de Evita. A subtração do cadáver da ex-primeira-dama, a seu turno, é a força propulsora de "Esa mujer", texto publicado por 
Rodolfo Walsh em 1965 e considerado, segundo lembra Juan Pablo Luppi (2012, p. 68) o melhor conto argentino do século XX em uma consulta a escritores e críticos publicada pela Editorial Alfaguara em 1999.

O enredo de "Esa mujer" apresenta, como ponto de partida, o encontro entre um escritor e um coronel. O diálogo entre as personagens transcorre no apartamento do oficial, localizado no décimo andar de um edifício portenho, contando apenas com a luz do sol como testemunha. Do alto, os olhos dos interlocutores passeiam por Buenos Aires e pelo rio da Prata, de maneira que tanto a claridade do dia quanto o distanciamento da cidade sugerem que aquele momento de encontro é propício a uma revelação. Supostamente, o coronel espera do escritor a entrega de alguns nomes e papéis. $O$ escritor, por sua vez, busca informações sobre o paradeiro do cadáver de uma mulher que, em momento algum, é nomeada. O leitor pode perceber, no entanto, que se trata do cadáver de Eva Perón em razão dos fatos reais mesclados por Rodolfo Walsh à narrativa ficcional.

A vastidão da cidade e do rio, observados da janela daquele apartamento, parece harmonizar-se com a imagem inicial do coronel, um homem alto e largo que bebe seu uísque com entusiasmo. (WALSH, 1986, p. 10) Contudo, a mudança de perspectiva, de fora para dentro do apartamento, altera a percepção do escritor acerca do semblante do oficial. O militar assume um tom sério e gradualmente atormentado à medida que relata um atentado a bomba sofrido por sua família naquele apartamento. Cada objeto danificado tem gravadas, em si, as marcas de duas sortes de dor: a dor dos que não se esqueceram da mulher não nomeada cujo corpo teria sido furtado pelo coronel em cumprimento a ordens superiores - e a dor dos moradores daquele ambiente. Mesmo em sua casa, o coronel coabita uma zona de impasse entre o público e o privado. Em torno da figura do militar, orbitam aqueles que reivindicam o cadáver da mulher e, também, sua esposa e sua filha, acometidas pelo trauma do atentado.
Ao mencionar a explosão da bomba, o coronel manuseia, delicadamente, uma pastorinha quebrada que compõe as ruínas de seu apartamento. Tal pastorinha é emblemática se associada às demais figuras femininas do conto: nenhuma delas passa incólume à presença do coronel. Sua filha, uma menina de doze anos, precisou ser submetida a um tratamento psiquiátrico, ao passo que sua esposa apresenta indícios de algum desequilíbrio emocional. A expressão de ira toma posse do coronel quando este menciona a situação de sua filha. À medida que o homem fala de si, de sua família e sobretudo da mulher de nome não pronunciado, a luz do dia se esvai. A penumbra invade o apartamento e, embora o coronel continue a falar, sua imagem desaparece a pouco e pouco diante de seu interlocutor.

Sintomático do desenrolar da trama, o momento do anoitecer é simbolicamente característico em diversas mitologias. Como postula Gilbert Durand (2002, p. 91), referindo-se à consideração de Bachelard de que uma só mancha negra é suficiente para nos colocar em estado de trevas, "a aproximação da hora crepuscular sempre pôs a alma humana nesta situação moral". No caso do coronel, com o avanço implacável da noite, seu atormentado espírito se sobrepõe progressivamente à consciência, incitando uma considerável mudança em sua enunciação discursiva. $O$ fim do dia envia para as sombras do apartamento não só a imagem do oficial como também a sua lucidez, sinalizando o peso do mito que recai sobre os dois homens que dialogam naquele espaço.

Ainda durante o diálogo, o escritor menciona outros militares vitimados por infortúnios após terem tido contato com o cadáver de Eva Perón. Esse ponto da conversa parece sugerir que a figura mítica de Evita paira como uma maldição sobre aqueles que esconderam seu corpo. Tal perspectiva coopera para nutrir o imaginário acerca do cadáver e para sacralizar "esa mujer" após sua morte. À observação do escritor sobre os outros militares, o coronel reage como quem está ciente da dinâmica do mito. Assim ele pondera: "- La fantasía popular - dice -. Vea cómo trabaja. Pero en el fondo no inventan nada. No 
hacen más que repetir." (WALSH, 1986, p. 11) Eis que, à semelhança da perspectiva de Barthes, o coronel reflete sobre uma característica geral do mito, intuindo corretamente acerca de sua elaboração por meio da linguagem e de sua alimentação em âmbito coletivo por repetições e releituras.

Essa acepção do mito, portanto, atua em estreita ligação com o imaginário social, já que este é, para Michel Maffesoli (2001, p. 76), "uma construção histórica, mas também o resultado de uma atmosfera e, por isso mesmo, uma aura que continua a produzir novas imagens." O mais relevante nesse sentido reside em que tal constatação se torna válida tanto para o conto "Esa mujer" quanto para sua abrangência social, entrelaçando de modo inextricável literatura e sociedade. Em outros termos, à medida que visita os mistérios em torno do mito sem para ele oferecer respostas definitivas, a narrativa de Rodolfo Walsh acaba por participar do processo de construção de novos sentidos e reforçar com novas imagens a aura a que se refere Maffesoli. É interessante observar, ainda, que boa parte da força narrativa do conto advém do fato de que a construção de significados do mito utiliza, como sujeito de reflexão, justamente uma personagem a quem, em virtude de sua posição política antagônica e de seu envolvimento indevido com o cadáver, não interessa o fortalecimento da figura de Eva Perón.

Além de ponderar sobre características que perpassam a elaboração dos mitos, isto é, sua construção por meio da linguagem e de um pensamento compartilhado socialmente, o coronel esboça sucinta e interessante comparação: “- La tumba de Tutankamón - dice el coronel -. Lord Carnavon [sic]. Basura." (WALSH, 1986, p. 11) Como quem deseja não crer, mas tampouco se arrisca a entrar no mérito da questão, a personagem alude ao evento que ficou conhecido como a "maldição do faraó", oriundo da crença na imprecação que recairia sobre aqueles que violassem a tumba de Tutancâmon. Na segunda década do século $X X$, cogitou-se realmente sobre a procedência da maldição pelo fato de Lord Carnavon, mecenas do arqueólogo Howard Carter, ter falecido menos de um mês após a abertura do túmulo. É possível que o coronel tenha se reportado à maldição como "basura" - lixo, porcaria - porque Lord Carnavon não estava presente no momento da abertura da tumba, tendo morrido no Cairo em razão de uma pneumonia e de uma infecção decorrente da picada de um mosquito. (MORLEY, 2005, p. 42) De toda sorte, a simples remissão ao ocorrido com Lord Carnavon revela a força do mito Eva Perón, chegando a ser comparado àquele de Tutancâmon na passagem em que o coronel tenta negar a existência de uma maldição argentina.

Mesmo diante de tamanha carga mítica, o coronel deseja apresentar sua versão dos fatos, conquanto esta não seja suficiente para, de algum modo, prejudicar o processo de mitificação e ainda que tal versão venha, possivelmente, fomentar a aura em torno de Evita. A personagem parece esperar que, a partir de seu relato, seja feita uma espécie de reparação histórica. Dentre suas linhas de defesa, destaca-se um argumento de autoridade: a afirmação de que ele, em virtude de seus conhecimentos de História, teria protegido o cadáver de várias sugestões e intentos de destruição. $O$ oficial justifica que sua persistência em manter a integridade do corpo funda-se em seu modo de analisar os eventos históricos: "-Porque yo he estudiado historia. Puedo ver las cosas con perspectiva histórica. Yo he leído a Hegel." (WALSH, 1986, p. 13)

Enquanto o coronel discorre sobre o dia em que encontrara o cadáver de Eva Perón, a escuridão cai sobre o apartamento "como en un teatro" (WALSH, 1986, p. 14), de forma que, em plena réplica àqueles que o acusam, o militar não mais se encontra sob os holofotes. Resta-lhe somente um assento na plateia, ofuscado pelo mito. Apesar de o oficial afirmar que "en la oscuridad se piensa mejor" (WALSH, 1986, p. 14), seus argumentos de defesa fragilizam-se na medida de sua própria invisibilidade. O escritor não pode enxergar o rosto do interlocutor, mas ouve, de algum ponto da sala, reflexões menos elaboradas e mais emotivas que aquelas observadas enquanto o sol ainda brilhava: "- Tuve que pagar la mortaja de mi bolsillo. Mil cuatrocientos pesos. Eso le 
demuestra, ¿eh? Eso le demuestra", e, um pouco adiante, "- Sí, pobre gente - el coronel lucha contra una escurridiza cólera interior -. Yo también soy argentino." (WALSH, 1986, p. 15)

Cumpre reconhecer, observando-se a linha de raciocínio de Gilbert Durand (2002, p. 91), que "a hora do fim do dia, ou a meia-noite sinistra, deixa numerosas marcas terrificantes: é a hora em que [...] os monstros infernais se apoderam dos corpos e das almas", monstros estes que, no caso de "Esa mujer", manifestam-se por meio dos demônios do passado do coronel, que demandam respostas quanto ao desaparecimento do mítico corpo. Mas, refém da escuridão voraz e com a razão perturbada pelos fantasmas de ações pretéritas e inconfessáveis, o coronel se vê na contingência de recorrer justamente ao mito que então tentara combater e que agora acaba por reforçar. Não é outro senão este o motivo de declarar, num arroubo de identificação: "Yo también soy argentino". Daí se depreende, por fim, a abrangência totalizante da figuração mítica de Eva Perón, com a qual, pressupõe-se, qualquer compatriota deva se identificar.

Ao cair da noite, apenas as cores vermelha e prateada alcançam os interlocutores, vindas de uma placa luminosa que alterna o logotipo "Coca-Cola" e o comando "Beba", como se ao coronel restasse somente esta alternativa. O escritor - personagem que narra o conto - observa a luz da placa "invadiendo la noche, la ciudad, el mundo". (WALSH, 1986, p. 16) Pode-se afirmar que sua reflexão sobre aquele produto icônico da sociedade de consumo cuja luz em certo sentido abarca o globo - perfila-se à potencialidade do mito. Para além daqueles intermitentes feixes de luz vermelha e prateada, o coronel se encontra à mercê da luz irradiada por Eva Perón. Se, conforme afirmado anteriormente, é ela quem Ihe nega os holofotes e Ihe destina um assento na escuridão da plateia, por outro lado é tão somente em função da existência mítica de Eva Perón que ao oficial é dada voz e oportunidade de tentar apaziguar o passado. Porém, à luta da personagem, travada no âmbito da linguagem, parece vetada qualquer possibilidade de solução.
A reabilitação histórica a que o coronel almeja é improvável em virtude da dificuldade do embate com Eva Perón, uma personagem histórica que, após um processo de inúmeras composições de sentido, torna-se, a um só tempo, quase descolada da História e inerentemente atrelada a ela. Ao mesmo tempo em que se torna um mito, portanto capaz de veicular discursos muito mais amplos que os do contexto histórico, é praticamente impossível pensar a história argentina sem Eva Perón. Precisamente nessa característica atribuída ao mito reside a inquietação e a crítica de Roland Barthes, para quem a figura mitológica não resulta de uma substância, mas de uma forma:

Lejana o no, la mitología sólo puede tener fundamento histórico, pues el mito es un habla elegida por la historia: no surge de la "naturaleza" de las cosas. Este habla es un mensaje y, por lo tanto, no necesariamente debe ser oral; puede estar formada de escrituras y representaciones: el discurso escrito, así como la fotografía, el cine, el reportaje, el deporte, los espectáculos, la publicidad, todo puede servir de soporte para el habla mítica. (BARTHES, 1999, p. 108)

Ao articular sua defesa, o coronel acaba emaranhado na trama composta pelos significantes que sustentam o mito. O oficial lembra que, quando encontrou o corpo sob os cuidados de um "galego" o espanhol que a embalsamou $\neg-$, a mulher estava nua e parecia uma virgem. Em seguida, o coronel se refere ao corpo de Eva como se fosse o de uma deusa. O militar ainda contribui para o reforço do mito Eva Perón ao compará-la a Jesus Cristo. Ele faz referência à ocasião em que alguns homens foram encarregados de transferir o corpo de uma urna a outra: “- Uno se desmayó. Lo desperté a bofetadas. Le dije: 'Maricón, ¿esto es lo que hacés cuando tenés que enterrar a tu reina? Acordate de San Pedro, que se durmió cuando lo mataban a Cristo.' Después me agradeció." (WALSH, 1986, p. 16) Além de comparar - cadáver a uma virgem, a uma deusa e a um messias, o coronel associa o corpo a um macho pelo fato de este ter sido guardado, durante algum tempo, em uma urna deixada na posição vertical.

Os vários adjetivos atribuídos pelo coronel a "esa mujer" sugerem a impossibilidade de apreender 
o mito em uma definição. Sob a perspectiva da hibridez, o mito Eva Perón guarda semelhanças com Joana D'Arc, personagem do texto Saint Joan, de George Bernard Shaw (2001). Ambas se afiguram como ponto de convergência de uma série de significantes: virgem, santa, homem, ignorante, vítima, visionária etc. As duas figuras femininas parecem ser tributárias da Antígona de Sófocles, heroína trágica que, como observa George Steiner em Antígonas: a persistência da lenda de Antígona na literatura, arte e pensamento ocidentais (1995), tem seu sacrifício consciente reverberado na literatura ocidental até a contemporaneidade.

Uma reflexão que aproxime Eva Perón de Joana D'Arc e de Antígona - sob a óptica da construção do mito - afigura-se razoável por apontar a impropriedade de interpretações reducionistas, pretensiosamente portadoras da chave que desvenda o fenômeno. O autor de "Esa mujer" parece estar ciente da porosidade da composição mítica e, por isso, conduz a narrativa para um final aberto. Não há resposta quanto ao enigma do paradeiro do cadáver. Resta apenas a vaga promessa do coronel de que tudo, um dia, será revelado.

\section{Considerações finais}

Ao ser concluído com um final aberto, o conto "Esa mujer" parece distanciar-se dos traços que caracterizam certa faceta da poética edificada por Rodolfo Walsh. Segundo observa Silvia Beatriz Adoue, um dos aspectos de maior relevo na obra do escritor e militante argentino consiste na resolução de enigmas, o que não ocorre no enredo de "Esa mujer". De acordo com Adoue, o desvendar de mistérios se faz presente “(..) na literatura policial, na sua obra investigativa, na atividade de inteligência na organização em que milita. Isto acontece porque a literatura, para Walsh, é também um lugar de reflexão individual e coletiva." (2008, pp. 13-4)

Graciela Foglia, por sua vez, observa certa inflexão na poética de Walsh após 1957, ano de publicação de Operación masacre. A perspectiva lançada por Foglia à obra de Walsh aponta o motivo por que o conto "Esa mujer", publicado em 1965, destoa de textos anteriores, em que Walsh havia ofertado respostas a enigmas:

En cuanto a las diferencias, se puede decir que si en los primeros textos la intervención de la policía y la resolución del enigma permiten reestablecer [sic] el orden perdido, o sea, reestablecer [sic] la vigencia de la ley, en los cuentos posteriores a Operación masacre (más próximos al policial negro, incluyen la saga del comisario Laurenzi) esto ya no ocurre. Walsh pasa de crear policías "simpáticos" (casi oprimidos por la sociedad) y asesinos "convictos", a crear policías y asesinos "angustiados", llenos de dudas y culpas. (FOGLIA, 2005, pp. 16-7)

Com efeito, o conto "Esa mujer" bem se coaduna com os primeiros escritos de Walsh não pelo viés da solução de um mistério, mas por promover a discussão, no âmbito da narrativa ficcional, de eventos históricos pertinentes à sociedade argentina. Segundo afirma Silvia Beatriz Adoue (2008, p. 5), Walsh "soube fazer da atividade literária um ato de reflexão sobre a história do seu país e da própria ação militante". Nessa linha de raciocínio, seu trunfo em "Esa mujer" jamais residiu em ofertar esclarecimentos sobre o paradeiro do cadáver. O que o conto desvela, em verdade, é a desconfortável situação do coronel - e do poder de fato do qual fazia parte -, encurralado entre o mito que invade o apartamento, a cidade, a noite, e um séquito que, simbolicamente, à porta do apartamento, não está disposto a esquecer Eva Perón.

\section{Referências}

ADOUE, Silvia Beatriz. Rodolfo Walsh, o criptógrafo: relações entre escrita e ação política na obra de Rodolfo Walsh. 2008. 210 p. Tese (Doutorado). Programa de Pós-Graduação em Língua Espanhola e Literaturas Espanhola e HispanoAmericana. Departamento de Letras Modernas da Faculdade de Filosofia, Letras e Ciências Humanas da Universidade de São Paulo. Manuscrito.

BARTHES, Roland. Mitologías. Trad. Hector Schmucler. 12. ed. México, DF; Madrid: Siglo XXI, 1999. $256 \mathrm{p}$.

BÍBLIA SAGRADA. N.T. Carta de Paulo aos Gálatas. Capítulo 2, versículo 20. Trad. João Ferreira de Almeida. Ed. rev. e atual. Brasília: Sociedade Bíblica do Brasil, 1969. 309 p. 
BORGES, Jorge Luis. El simulacro. El hacedor. In: Obras completas. 1923-1972. Buenos Aires: Eméce, 1974. 1170 p

La biblioteca de Babel. Ficciones. In: Obras completas. 1923-1972. Buenos Aires: Eméce, 1974. 1170 p.

DURAND, Gilbert. As estruturas antropológicas do imaginário. Trad. Hélder Godinho. 3. ed. São Paulo: Martins Fontes, 2002. 552 p.

FOGLIA, Graciela. Rehacer y resistir: el proceso de escritura de "Operación Masacre" de Rodolfo Walsh. 2005. 178 p. Tese (Doutorado). Programa de Pós-Graduação em Língua Espanhola e Literaturas Espanhola e Hispanoamericana. Departamento de Letras Modernas da Faculdade de Filosofia, Letras e Ciências Humanas da Universidade de São Paulo. Manuscrito.

LUPPI, Juan Pablo. Seis cuentos en busca de un autor. El declive del comisario Laurenzi en el proyecto de Rodolfo Walsh. Badebec. Centro de Estudios de Teoría y Crítica Literaria. Rosario: Facultad de Humanidades y Artes de la Universidad Nacional de Rosario, n. 2, p. 63-103, mar., 2012.

MAFFESOLI, Michel. O imaginário é uma realidade. Revista Famecos. Porto Alegre, n. 15, p. 74-82, 2001

MORLEY, Jacqueline. Inside the Tomb of Tutankhamun. Brighton: The Salariya Book Co. Ltd.; Book House, 2005. 48 p.
ONETTI, Juan Carlos. Ella. In: Cuentos completos (1933-1993). Espanha: Editorial Alfaguara, 1994. $468 \mathrm{p}$.

PERÓN, Eva. La Razón de Mi Vida. Buenos Aires: Ediciones Peuser, 1951. 317 p.

Mi Mensaje. [s/l; s/d]. Disponível em: <http://www.pjmerlo.org.ar/system/contenido.php?i d_cat=189> Página eletrônica do Partido Justicialista de Merlo. Acesso em: 10 abr. 2012.

SÓFOCLES. Antígone. Trad. J. B. de Mello e Souza. Versão para eBook. Digitalização do livro em papel. "Clássicos Jackson". vol. XXII, p. 11. Disponível em <eBooksBrasil.com> Acesso em: 15 jul. 2011.

STEINER, George. Antígonas: a persistência da lenda de Antígona na literatura, arte e pensamento ocidentais. Lisboa: Relógio D’Água, 1995. 360 p.

SHAW, George Bernard. Saint Joan. A Chronicle Play in Six Scenes and an Epilogue. Londres: Penguin Classics, 2001. 192 p.

VIÑAS, David. La señora muerta. In: Las malas costumbres. Buenos Aires: Editorial Jamcana, 1963. 175 p.

WALSH, Rodolfo. Esa mujer. In: . Los oficios terrestres. Buenos Aires: Ediciones de La Flor, $\quad 1986$.

\section{COMO CITAR ESSE ARTIGO}

MALLOY, Letícia; PELINSER, André Tessaro. Eva Perón: a mulher e o mito no conto "Esa mujer", de Rodolfo Walsh. Signo, Santa Cruz do Sul, v. 41, n. 72, out. 2016. ISSN 1982-2014. Disponível em: <https://online.unisc.br/seer/index.php/signo/article/view/6937>. Acesso em: doi: http://dx.doi.org/10.17058/signo.v41i72.6937. 